\title{
Will US Congress fill vacuum?
}

THE French space agency, CNES, plans to spend more on basic science, lifting the proportion of its funds from 6-7 per cent now to 10 per cent by 1990 . But this is only a target, according to research director Isaac Revah last week. One of the imponderables is whether US participation in the joint Topex/Poseidon oceanographic satellite, France's biggest project so far in basic space science, will survive the automatic budget-cutting mechanisms to which the US government is now committed (see Nature 318, 495; 1985).

So CNES is hatching contingency plans for Poseidon, the French half of the project. British or Scandinavian participation is being mentioned as an alternative. But the possibility of collaboration with the Soviet Union, for which there are many
CNES precedents, is "certainly not" on. The Poseidon satellite instruments, consisting of a high-resolution altimeter, a troposphere radiometer and positioning equipment capable of fixing orbital positions to within $10-15 \mathrm{~cm}$. have an obvious military interest.

The US half of the project, Topex, has also thrown up problems of secrecy. The purpose of these instruments is to infer ocean currents from measurements of ocean topography. Nominally, the project is a civil enterprise. But the US Department of Defense has slapped restrictions on the details of the instrumentation. France, through CNES, has retaliated by offering the United States only black-box descriptions of what the Poseidon instruments will do. If the US National Aero-

\section{Soviet science}

\section{Making policy by TV camera}

A REMARKABLE innovation in television programming, allowing public questioning of Soviet government officials, seems to have been part of the preparation for the Soviet Union's 27th Party Congress in February. On 29 November, Soviet television stations broadcast a phone-in with viewers' questions about "accelerating scientific and technical progress", a keynote phrase of all Soviet economic documents of the past decade.

The panel included Academician Anatolii P. Aleksandrov, president of the Soviet Academy of Sciences, two vicepresidents of the academy (Evgenii $P$ Velikhov and Yurii A. Ovchinnikov), two deputy prime ministers (Ivan S. Silaev and Gurii I. Marchuk) and the chairman of the State Committee for Discoveries and Inventions, Ivan S. Nayashkov. The producers seem to have created an atmosphere of spontaneity, but since it had also been possible to telephone questions in advance, and since the questioners' voices were never heard, it is impossible to know how many replies were genuinely unprepared.

Nevertheless, the programme does seem to have reflected genuine public criticism and doubts. Here are summaries of some of the exchanges:

Q: Why are the power sets of the Leningrad, Ignalina and Cheronbyl nuclear power stations built in five different - and flawed - designs?

A: We're working on it.

Q: Why does it take more than 12 years for a "practical invention" to be introduced into the economy?

A: It takes only six years, and we are trying to reduce this time

Q: What are personal computers, and won't they make people "unlearn" how to count? (This question was from a. school- boy, presumably too young to have started the new compulsory computer studies course.)

A: On the contrary, they expand the hu-

Q: What is being done to overcome "highhanded administration" and "the cult of the director" in certain scientific establishments?

A: The powers of directors are now being widened, but we have the means to counteract the negative features of highhanded administration.

Some questions, however, seem to have been specially picked to allow the panel to expatiate on new plans and proposals - the concentration in the new Five-Year Plan on machine tools, the establishment of biotechnology centres in rural areas or of a laboratory to monitor how the young generation in schools accept computer technology, and "whether it will do any harm to their development".

A question to Academician Ovchinnikov in his role as chairman of the AllUnion Society for the Struggle for Sobriety itself answered one question that has been puzzling many Soviet citizens, not to mention Soviet-watchers abroad - why have scientists in particular been coopted in such force into the anti-alcoho movement?

Ovchinnikov's answer is that the acceleration of scientific and technical progress requires increased labour discipline, that is, the elimination of drunkenness. Ovchinnikov, himself, it appears, is in favour of total abstinence.

Other questions related to recent policy decisions such as the merging of the medical and microbiological industries, and the commitment to thermonuclear power emphasized at the Geneva summit. Vera Rich man capacity for thought. nautics and Space Administration (NASA) fails to get its money, Poseidon will be flown on a French Earth observation satellite, one of the SPOT series, in 1990-91. "We don't need technology transfer in this field", Revah says.

The French space programme for the next few decades, now becoming clear in its outlines, is diverse and ambitious. In basic science, according to Revah, more attention will be paid to Earth science, but not at the expense of astronomy, supported mainly through agreements with the Soviet Union. On the hardware side, France is committed to the development of the Hermes space shuttle, the cryogenic third stage of Ariane, and participation in the European contribution to the US space station, the separate vehicle called Columbus.

For the rest, the following projects and programmes are on the cards.

- A satellite called Magnolia for precise measurement of the Earth's magnetic field, possibly to be built before 1995. (A similar project for the measurement of gravitional fields, called Gradio, has encountered technical snags and may be put back.) Beyond that, CNES prefers to talk of programmes rather than particular satellites, but there is an inclination to concentrate on measurements that will help to define the hydrological cycle in the troposphere, with obvious applications in climatology. By 1995, the officials say, it may also be possible to make direct measurements of the ground motions expected from plate tectonics and at geological faults, either by the comparison of successive high-resolution photographs or with the help of fixed ground beacons.

- In astronomy, priority will probably be given to Franco-Soviet collaboration on Vesta, a mission to Venus and the asteroids, that will cost France FF600 million. But there is a host of other projects, suggested by the French community, competing for CNES funds. These include a low orbiter for the study of the internal structure of Jupiter, a Mars rover that would look for traces of water, a radiointerferometer called Trio and participation in the proposed European Space Agency (ESA) high-resolution spectrographic $\mathrm{X}$-ray telescope. The only certainty is that CNES will not be able to support all these projects.

- On manned spaceflight, CNES hopes to arrange a long-duration space flight with the Soviet Union so as to engage the French space medicine community; as always, it is looking for industrial interest in the exploitation of microgravity environments.

This year, French spending on these activities will have amounted to FF150 million in bilateral programmes, almost entirely on instrumentation, plus FF200 million on the ESA science budget. This makes a total of FF350 million, compared with the goal for 1990 of FF600 million.

Robert Walgate 